\title{
Pullout Strength of Anterior Lumbar Interbody Fusion Plates: Fixed Versus Variable Angle Screw Designs
}

Zachary S. Hadley, Daniel K. Palmer, Paul A. Williams and Wayne K. Cheng*

Department of Orthopaedic Surgery, Loma Linda University, Loma Linda, California, USA

\author{
Abstract \\ Purpose: To compare the pullout loads of variable versus fixed angle screws in anterior lumbar interbody fusion \\ (ALIF) plate/screw constructs in both foam and cadaveric models.
}

Methods: An ALIF plate was secured to a $0.160 \mathrm{~g} / \mathrm{cm}^{3}$ polyurethane foam block $(\mathrm{N}=10)$ with fixed or equivalentlypositioned variable angle screws and pulled out at $1 \mathrm{~mm} / \mathrm{min}$ to failure. Embalmed human vertebral pairs $(\mathrm{N}=10)$ were similarly utilized to compare fixed versus variable angle plate/screw constructs for pullout strength.

Results: There was no statistically significant difference between fixed and variable angle plates for either foam ( $p=0.6$ ) or vertebral specimens $(p=0.3$ ) based on maximum load or stiffness. The maximum load for the vertebral specimens was on average $39 \%$ of that for the foam $(p=0.001)$ and the stiffness was about $55 \%$ of that for the foam $(p=0.001)$

Conclusions: In this study, no statistically significant difference in pullout strength or stiffness was found between fixed and variable angle ALIF plate/screw constructs. However, the embalmed cadaveric bone model was shown to be statistically weaker in pullout strength and stiffness when compared to the foam model. This study suggests that the foam model may not always be representative of the cadaveric model in the magnitude of load, but may still provide good comparative results between different designs.

Keywords: ALIF; Cadaver; Lumbar plate; Polyurethane foam; Pullout; Screw

\section{Introduction}

Although internal fixation of the spine is an established practice, much is not known about the effects that various design factors have on the performance of instrumentation employed [1-3]. Considerable work exists concerning screw pullout forces $[1,4,5]$ and plate/screw constructs for anterior fusion of the cervical spine [2,6-8], but less work exists examining these issues for the lumbar spine. For anterior fixation in the cervical spine, fixed versus variable angle plates with different screw angulations and lengths have been recently studied $[2,6]$. In order to reduce the heterogeneity in density within and between cadaveric samples, these studies utilized a bone foam model for their tests. It has been demonstrated in both cervical and lumbar regions that the bone mineral density has a significant effect on screw pullout and cutout strength [8-10]. Anterior lumbar interbody fusions (ALIF) utilize a cage and work relatively well for the treatment of degenerative disc disease $[11,12]$. However, the fixation strength of these cages in an overtly unstable spine usually requires the assistance of either anterior or posterior instrumentation for additional support [13-16]. Although there are studies comparing anterior lumbar plates to posterior instrumentation $[3,14,16]$, biomechanical comparisons of fixed verses variable angle lumbar plate constructs remain lacking from the literature.

Previous studies have documented that factors such as number of screws, length, diameter, and shape can influence stability and pullout load [17-20]. The purpose of this study is to compare the pullout loads of fixed verses variable angle lumbar plates in both cadaveric and foam block models.

\section{Materials and Methods}

\section{Materials}

This study was performed in two stages. Both embalmed human cadaveric spines and polyurethane foam blocks (Pacific Research Laboratories, Vashon, WA) were tested. Both cadaveric and foam models utilized the same plate/screw construct (LANX, Inc, Broomfield, CO, USA) (Figure 1). The screws were $20 \mathrm{~mm}$ in length and $6.0 \mathrm{~mm}$ in diameter. Plate overall length was $34 \mathrm{~mm}$ with a hole center to hole center distance of $21 \mathrm{~mm}$. Plate overall width was $26.5 \mathrm{~mm}$ with a hole center to hole center distance of $14 \mathrm{~mm}$. The plates utilized fixed screw angles of 2 degrees convergent per side in the axial plane and 4 degrees divergent per side in the sagittal plane. Variable screw angulations ranged from 4 degrees diverging to 15 degrees converging per side in the axial plane and from 2 degrees converging to 16 degrees diverging per side in the sagittal plane. Plastic drill guides were used to drill all holes with 2 degrees convergence axially and 4 degrees divergent sagittally for both fixed and variable angle constructs.

Four embalmed human cadaveric spines from T12-S1 were utilized for testing. Anteroposterior and lateral X-rays were obtained to check for defects in the specimens that could adversely affect results. All specimens underwent dual energy X-ray absorptiometry scans to determine the bone mineral density (BMD) of the specimens. Inclusion/exclusion criteria included no major defects and no significant differences in BMD for the specimens. The spines were then harvested into vertebral pairs with the posterior elements removed. Variable and fixed angle constructs were instrumented on each specimen at the left and right anterolateral aspects which allowed for pairwise analysis. Vertebrae were measured to ensure that no screw trajectories overlapped. The plates and screws were installed according to established surgical practice. Polyurethane foam with a density

*Corresponding author: Wayne K. Cheng, Department of Orthopaedic Surgery, School of Medicine, Loma Linda University, 11406 Loma Linda, California 92354 USA, Tel: (909) 558-6444; Fax: (909) 558-6118; E-mail: md4spine@yahoo.com

Received March 08, 2012; Accepted May 21, 2012; Published May 23, 2012

Citation: Hadley ZS, Palmer DK, Williams PA, Cheng WK (2012) Pullout Strength of Anterior Lumbar Interbody Fusion Plates: Fixed Versus Variable Angle Screw Designs. J Spine 1:118. doi:10.4172/2165-7939.1000118

Copyright: (c) 2012 Hadley ZS, et al. This is an open-access article distributed under the terms of the Creative Commons Attribution License, which permits unrestricted use, distribution, and reproduction in any medium, provided the original author and source are credited. 
of $0.160 \mathrm{~g} / \mathrm{cm}^{3}$ was also used to evaluate pullout strength of ALIF plate constructs. This density has been used to simulate osteoporotic cancellous bone in previous validated studies $[1,2,4]$.

\section{Pullout tests}

The biomechanical setup for the pullout tests was similar to that previously described in the literature for comparable cervical plate pullout studies $[2,6]$. Each vertebral pair and foam block had a $6 \times 6$ $\mathrm{mm}$ groove (dado) machined into it to allow the holding clamp to be placed beneath the plate so that it could be pulled directly and evenly in an axial manner. The specimen with the ALIF plate construct was clamped into a fixture (Figure 1). A Servo Hydraulic materials testing machine (Instron, Norwood, MA, USA) applied a displacement of $1 \mathrm{~mm} / \mathrm{min}$ as has been applied in previous studies [2,6]. Failure was defined as the load at which maximum pullout force was attained.

\section{Statistical analysis}

Independent $t$-tests were employed to test for differences between the fixed and variable angle plates as well as for the difference between foam and cadaveric specimens.

\section{Results}

There was no statistically significant difference $(p=0.15)$ found for BMD between any of the vertebral specimens (Table 1). There was no statistically significant difference between fixed and variable angle plates for either foam $(\mathrm{p}=0.6)$ or vertebral specimens $(\mathrm{p}=0.3)$ based on maximum load or stiffness (Figure 2 and 3 ). The average pullout strength in the foam group for variable angle plates was $<5 \%$ higher than that for fixed angle plates (Table 2). Conversely, in the cadaveric group the average pullout load for the variable angle plates was approximately $30 \%$ less than that for fixed angle plates (Table 2). For

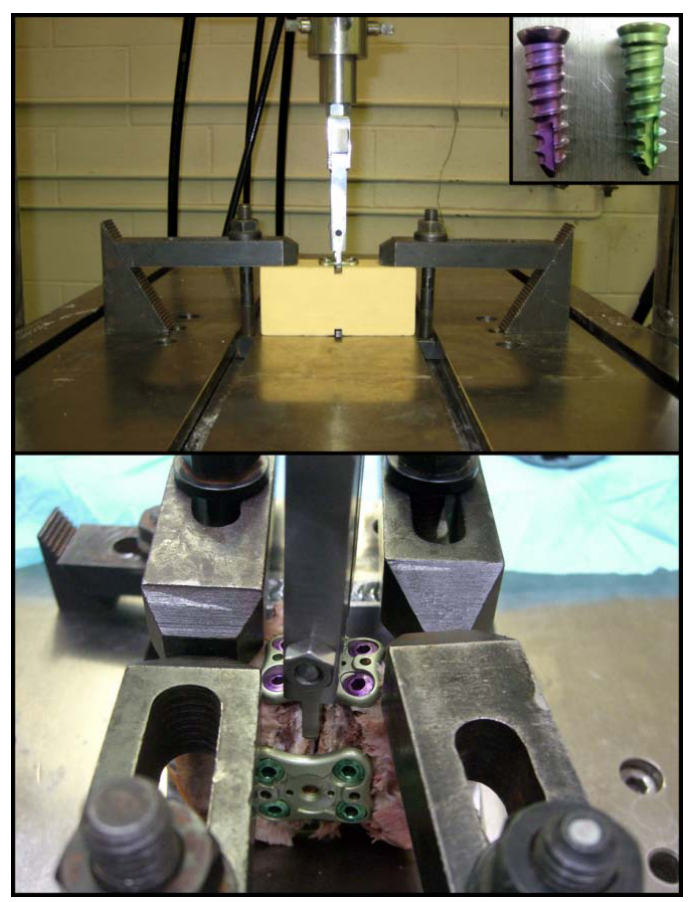

Figure 1: The biomechanical pullout setup for foam blocks is shown on top. The variable (purple) and fixed (green) angle screws are shown in the upperright corner. The biomechanical pullout setup for vertebral pairs is shown below.

\begin{tabular}{|l|l|l|l|l|}
\hline \multirow{2}{*}{ Specimen } & \multirow{2}{*}{ Gender } & \multirow{2}{*}{ Age (yrs) } & \multicolumn{2}{|l|}{ BMD $\mathbf{( g / \mathbf { c m } ^ { 2 } )}$} \\
\cline { 5 - 6 } & & Mean & Std \\
\hline 1 & F & 75 & 0.700 & 0.041 \\
\hline 2 & F & 75 & 0.757 & 0.090 \\
\hline 3 & M & 75 & 0.793 & 0.033 \\
\hline 4 & F & 75 & 0.642 & 0.032 \\
\hline
\end{tabular}

Table 1: Summary data on the bone mineral density (BMD) of the 4 cadaveric spines used.

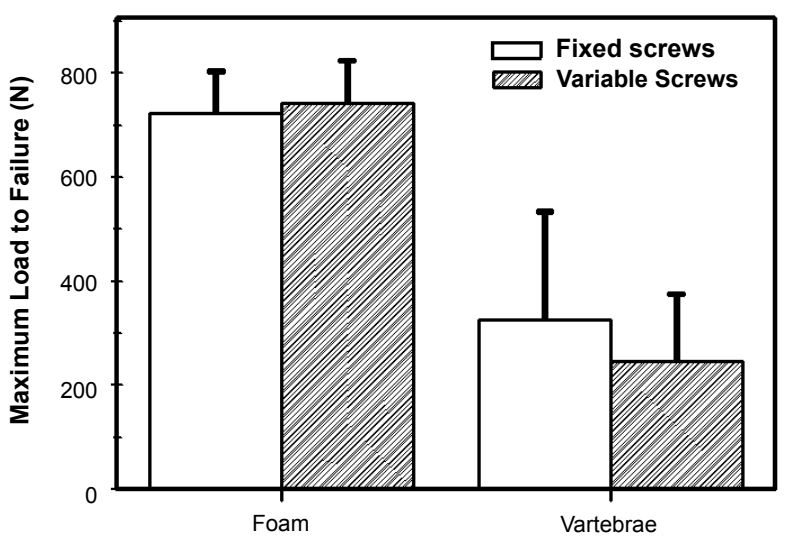

Figure 2: Mean pullout loads $(\mathrm{N})$ and standard deviations of variable and fixed angle plate/screw constructs in foam and cadaveric models.

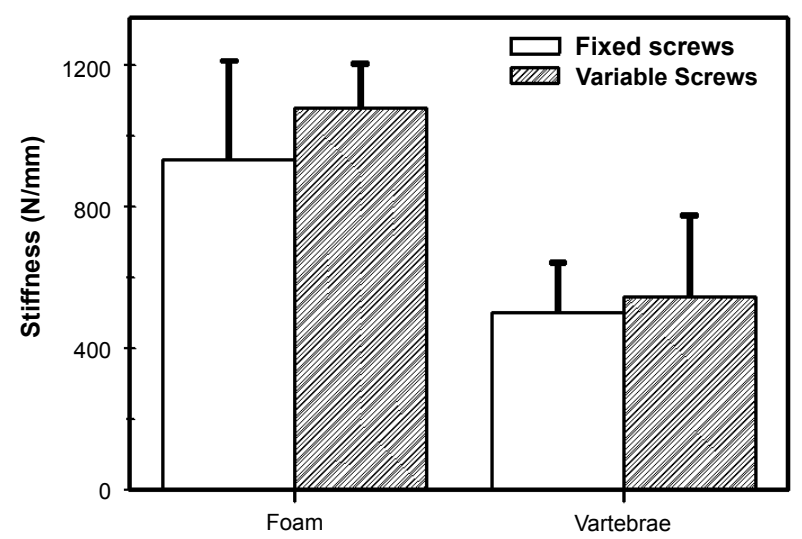

Figure 3: Mean stiffness $(\mathrm{N} / \mathrm{mm})$ and standard deviations of variable and fixed angle plate/screw constructs in foam and cadaveric models.

\begin{tabular}{|l|l|l|l|}
\hline Screw Design & Foam Blocks $\mathbf{( N = 1 0 )}$ & Vertebrae $\mathbf{( N = 1 0 )}$ & Ratio (Vert/Foam) \\
\hline Fixed & $721.9 \pm 81.8$ & $325.1 \pm 208.2$ & $45.03 \%$ \\
\hline Variable & $742.1 \pm 81.5$ & $247.0 \pm 128.5$ & $33.28 \%$ \\
\hline
\end{tabular}

Table 2: Descriptive statistics for the maximum load $(N)$ to failure with fixed or variable angle plate (mean \pm standard deviation).

the stiffness, variable angle plate constructs averaged about 15\% higher than fixed angle plate constructs in both foam and cadaveric specimens (Table 3).

There was a statistically significant difference $(\mathrm{p}<0.05)$ found between the foam and vertebral specimens. This result held for both maximum load and stiffness (Table 2 and 3; Figure 4). The maximum load for the vertebral specimens was on average $39 \%$ of that for the foam $(\mathrm{p}=0.001)$ and the stiffness was about $55 \%$ of that for the foam $(\mathrm{p}=0.001)$. 


\begin{tabular}{|l|l|l|l|}
\hline Screw Design & Foam Blocks $\mathbf{( N = 1 0 )}$ & Vertebrae $\mathbf{( N = 1 0 )}$ & Ratio (Vert/Foam) \\
\hline Fixed & $933.7 \pm 278.3$ & $501.9 \pm 140.1$ & $53.75 \%$ \\
\hline Variable & $1080.7 \pm 123.6$ & $603.5 \pm 278.7$ & $55.84 \%$ \\
\hline
\end{tabular}

Table 3: Descriptive statistics for the Stiffness $(\mathrm{N} / \mathrm{mm})$ with fixed or variable angle plate (mean \pm standard deviation).

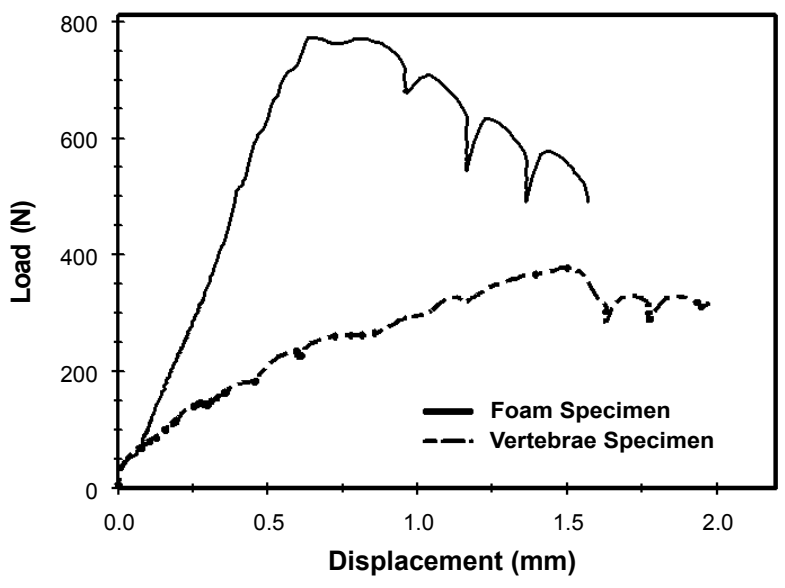

Figure 4: Load/displacement curves of foam and cadaveric models.

\begin{tabular}{|l|l|l|}
\hline & Fixed & Variable \\
\hline DiPaola et al., 2007 & $288.4 \pm 37.7(13.1 \%)$ & $297.7 \pm 41.3(13.9 \%)$ \\
\hline Present Study & $721.9 \pm 81.8(11.3 \%)$ & $742.1 \pm 81.5(11.0 \%)$ \\
\hline
\end{tabular}

Table 4: Comparison of maximum load $(\mathrm{N})$ to failure of the fixed and variable plate constructs in foam blocks from a previous study with cervical plates and the present study with lumbar plates. Shown are the mean \pm 1 std and the coefficient of variation $(\mathrm{CV}=\mathrm{std} / \mathrm{mean} \times 100 \%)$.

\section{Discussion}

The purpose of this study was to examine the differences in pullout strength between fixed and variable angle ALIF plate/screw constructs. The adequacy of a foam block model compared to an embalmed cadaveric model was also investigated. Both embalmed cadaveric and foam block models have been employed in the literature $[2,6,7,21]$. In both foam and cadaveric models no statistical differences were observed between fixed and variable angle plate/screw constructs. The foam block model, however, yielded significantly more resistance to pullout than the embalmed cadaveric model $(\mathrm{p}=0.001)$.

Variable verses fixed angle constructs each have advantages and pitfalls. Variable angle constructs theoretically allow angling of the screw to place the screw in stronger bone, such as near the endplate or to maximize screw length. Fixed angle constructs do not allow toggling at the plate/screw interface, which may provide an advantage. However a recent study [2] in the cervical spine showed that a 90 degree construct actually outperformed angled "up and in" constructs which current teaching has stated is the strongest construct. In our study there was no difference between fixed or variable angle constructs. The maximum loads in this study using $20 \mathrm{~mm}$ by $6.0 \mathrm{~mm}$ screws in the foam model were 2.5 -fold higher (Table 4 ) than the loads obtained by DiPaola et al. [2] with $15 \mathrm{~mm}$ by $4.0 \mathrm{~mm}$ screws. The previous study utilized cervical plates and screws whereas this study used lumbar plates and screws. However, the variance proportional to the mean $(\mathrm{CV})$ was comparable between the two studies.

We found that an ALIF plate in the foam block model (density = $0.160 \mathrm{~g} / \mathrm{cm}^{3}$ ) had significantly greater pullout than in the embalmed cadaveric model $(\mathrm{p}=0.001)$. Previous studies have examined biomechanical properties of screw pullout forces in both of these models $[1,2,4,21]$. However, many of these studies employed the foam model for single screw pullouts and did not investigate plate/screw constructs. Although the magnitude of the pullout forces were different between the two models (foam and cadaveric), the comparison between variable and fixed angle plate/screw constructs were comparable. Therefore, this study would suggest that the foam model may not always be representative of the cadaveric model in the magnitude of load, but may still provide good comparative results between different designs.

One limitation of this study is the relevancy of embalmed and foam block in vitro models to the true characteristics of the lumbar spine in vivo. Being able to extrapolate from the in vitro model to the in vivo environment is always an issue. Paired analysis was utilized to eliminate potential variables in the cadaveric model, however, and the results observed here are comparable and consistent with other studies $[2,6,22]$. Another limitation is that only one implant design was studied and while we found no difference between fixed and variable angle plates in this system, this may not translate to other designs. Thirdly, we examined pullout strength as the primary outcome. While pullout testing provides a simple means of comparing relative stabilities among constructs, ALIF plates have other modes of failure in vivo, such as failing in shear from sagittal and coronal plane motion with screw cutout or breakage rather than pullout. Further studies are needed to look at other plate/screw characteristics in anterior lumbar plating systems such as screw length, diameter, angle positioned and differing modes of failure. Furthermore, studies are needed to compare embalmed, fresh frozen and differing foam densities to determine which substance is most suitable to be used for further pullout testing.

\section{Conclusions}

In this study, no statistically significant difference in pullout strength or stiffness was found between fixed and variable angle ALIF plate/screw constructs. However, the embalmed cadaveric bone model was shown to be statistically weaker in pullout strength and stiffness when compared to the foam model. This study suggests that the foam model may not always be representative of the cadaveric model in the magnitude of load, but may still provide good comparative results between different designs.

\section{Acknowledgments}

The authors would like to thank Lanx, Inc (Broomfield, CO, USA) for providing necessary plates and screws, Elisabeth Clarke and Mary Kolb for all of their administrative help, and Serkan Inceoglu, PhD, for his help revising the manuscript

\section{References}

1. Conrad BP, Cordista AG, Horodyski M, Rechtine GR (2005) Biomechanical evaluation of the pullout strength of cervical screws. J Spinal Disord Tech 18: 506-510.

2. DiPaola CP, Jacobson JA, Awad H, Conrad BP, Rechtine GR 2nd (2007) Screw pull-out force is dependent on screw orientation in an anterior cervical plate construct. J Spinal Disord Tech 20: 369-373

3. Johnson WM, Nichols TA, Jethwani D, Guiot BH (2007) In vitro biomechanical comparison of an anterior and anterolateral lumbar plate with posterior fixation following single-level anterior lumbar interbody fusion. J Neurosurg Spine 7: 332-335.

4. Brown GA, McCarthy T, Bourgeault CA, Callahan DJ (2000) Mechanical performance of standard and cannulated $4.0-\mathrm{mm}$ cancellous bone screws. $J$ Orthop Res 18: 307-312.

5. Thompson JD, Benjamin JB, Szivek JA (1997) Pullout strengths of cannulated and noncannulated cancellous bone screws. Clin Orthop Relat Res 241-249.

6. Dipaola CP, Jacobson JA, Awad H, Conrad BP, Rechtine GR 2nd (2008) Screw orientation and plate type (variable- vs. fixed-angle) effect strength of fixation for in vitro biomechanical testing of the Synthes CSLP. Spine J 8: 717-722. 
7. Griffith SL, Zogbi SW, Guyer RD, Shelokov AP, Contiliano JH, et al. (1995) Biomechanical comparison of anterior instrumentation for the cervical spine. J Spinal Disord 8: 429-438

8. Reitman CA, Nguyen L, Fogel GR (2004) Biomechanical evaluation of relationship of screw pullout strength, insertional torque, and bone mineral density in the cervical spine. J Spinal Disord Tech 17: 306-311.

9. Akbay A, Bozkurt G, Ilgaz O, Palaoglu S, Akalan N, et al. (2008) A demineralized calf vertebra model as an alternative to classic osteoporotic vertebra models for pedicle screw pullout studies. Eur Spine J 17: 468-473.

10. Lim TH, An HS, Evanich C, Hasanoglu KY, McGrady L, et al. (1995) Strength of anterior vertebral screw fixation in relationship to bone mineral density. $J$ Spinal Disord 8: 121-125

11. Oxland TR, Lund T (2000) Biomechanics of stand-alone cages and cages in combination with posterior fixation: a literature review. Eur Spine J 9: S95-S101.

12. Zdeblick TA, Phillips FM (2003) Interbody cage devices. Spine (Phila Pa 1976) 28: S2-S7.

13. Blumenthal SL, Ohnmeiss DD; NASS (2003) Intervertebral cages for degenerative spinal diseases. Spine J 3: 301-309.

14. Nichols TA, Yantzer BK, Alameda S, Johnson WM, Guiot BH (2007) Augmentation of an anterior lumbar interbody fusion with an anterior plate or pedicle screw fixation: a comparative biomechanical in vitro study. J Neurosurg Spine 6: 267-271.
15. Sasso RC, Kitchel SH, Dawson EG (2004) A prospective, randomized controlled clinical trial of anterior lumbar interbody fusion using a titanium cylindrical threaded fusion device. Spine (Phila Pa 1976) 29: 113-122.

16. Tzermiadianos MN, Mekhail A, Voronov LI, Zook J, Havey RM, et al. (2008) Enhancing the stability of anterior lumbar interbody fusion: a biomechanical comparison of anterior plate versus posterior transpedicular instrumentation. Spine (Phila Pa 1976) 33: E38-E43.

17. Chao CK, Hsu CC, Wang JL, Lin J (2008) Increasing bending strength and pullout strength in conical pedicle screws: biomechanical tests and finite element analyses. J Spinal Disord Tech 21: 130-138.

18. Errico T, Uhl R, Cooper P, Casar R, McHenry T (1992) Pullout strength comparison of two methods of orienting screw insertion in the lateral masses of the bovine cervical spine. J Spinal Disord 5: 459-463.

19. Hsu CC, Chao CK, Wang JL, Hou SM, Tsai YT, et al. (2005) Increase of pullout strength of spinal pedicle screws with conical core: biomechanical tests and finite element analyses. J Orthop Res 23: 788-794.

20. Suzuki T, Abe E, Okuyama K, Sato K (2001) Improving the pullout strength of pedicle screws by screw coupling. J Spinal Disord 14: 399-403.

21. Cordista A, Conrad B, Horodyski M, Walters S, Rechtine G (2006) Biomechanical evaluation of pedicle screws versus pedicle and laminar hooks in the thoracic spine. Spine J 6: 444-449.

22. Chapman JR, Harrington RM, Lee KM, Anderson PA, Tencer AF, et al. (1996) Factors affecting the pullout strength of cancellous bone screws. J Biomech Eng 118: 391-398. 